\title{
A EDUCAÇÃO MATEMÁTICA COMO INFLUENCIADORA NAS PRÁTICAS DE ENSINO DO PIBID
}

\author{
The Mathematics Education as influential in Practice Teaching PIBID
}

\author{
Dailson Evangelista Costa \\ Mônica Suelen Ferreira de Moraes ${ }^{1}$ \\ Tadeu Oliver Gonçalves ${ }^{2}$
}

\section{RESUMO}

Este trabalho mostra algumas das contribuições que o programa PIBID de Araguaína proporcionou aos bolsistas de Matemática durante dois anos. Dentre elas, é destacado o processo de reflexão-investigação, caracterizado como influenciador na postura dos bolsistas com relação à Matemática, direcionando-os para a Educação Matemática. A justificativa é que houve influência direta dos bolsistas nas atividades desenvolvidas, mostrando preocupações com o ensino de Matemática. Adotamos o método de exemplificação das práticas envolvendo a interdisciplinaridade (FAZENDA, 2002), juntamente com os pressupostos teóricosdo trabalho com projetos (HERNÁNDEZ; VENTURA, 1998), conduzidos por bolsistas das Licenciaturas em Matemática, História, Letras e Geografia. A partir de exemplos de atividades, destacamos um exercício de reflexão que aconteceu durante o desenvolvimento do programa. Esse exercício remete à seguinte indagação:que perspectivas o PIBID proporcionou, especificamente aos bolsistasde Matemática, com relação às práticas de ensino? Como resultado, mostramos as influências do PIBID na construção de um educador matemático reflexivo-investigativo.

Palavras-chave: Educação Matemática; Investigação; influências do PIBID; Iniciação à Docência; Educador.

\begin{abstract}
This paper shows some of the contributions that the program PIBIDfrom Araguaína provided to the scholarshipstudents of mathematicsfor two years. Among them, it is emphasized the process of reflection-investigation characterized as an influence in the attitude of these scholarshipstudents towards Mathematics directing them to Mathematics Education. The reason is that there was a direct influence on the activities of the scholarshipstudents, showing concerns about the teaching of mathematics. We adopted the method of exemplification of the practices involving interdisciplinarity (FARM, 2002) along with the theoretical assumptions of the work with projects (Hernández; VENTURA, 1998) conducted by the undergraduate scholarship studentsof Mathematics, History, Literature and Geography.From examples of
\end{abstract}

\footnotetext{
${ }^{1}$ Licenciados em Matemática, respectivamente, pela Universidade Federal do Tocantins (UFT) e Universidade do Estado do Pará (UEPA). Mestrandos do Programa de Pós-Graduação em Educação em Ciências e Matemática (PPGECM), do Instituto de Educação Matemática e Científica (IEMCI), da Universidade Federal do Pará (UFPA). E-mails: dailson_mat@ hotmail.com; monicasuelen@yahoo.com.br.

${ }^{2}$ Professor do Programa de Pós-Graduação em Educação em Ciências e Matemáticas (PPGECM) do Instituto de Educação Matemática e Científica (IEMCI/UFPA).

AMAZÔNIA - Revista de Educação em Ciências e Matemáticas V.8 - no 16 - jan. 2012/jun. 2012, p..
} 
activities, we highlight a reflection that took place during the development of the program. This exercise leads to the following question: what perspectives the PIBID provided, specifically to the scholarship students of Mathematics, in relation to the teaching practices? As a result, we show the influences of PIBID in the building of a reflective-investigative mathematics educator.

Key words: Mathematics Education; Research; influences of PIBID; Introduction to Teaching; Educator.

\section{INTRODUÇÃO}

Não apenas no Tocantins, mas em todos os Estados brasileiros, se não, em quase todo o mundo, o ensino de Matemática passa por muitas mudanças principalmente com as influências da Educação Matemática, uma vez que, com o advento das novas tecnologias, principalmente, os softwares, faz-se necessário que haja uma melhor preparação por parte dos professores. Da mesma formaexistem outras metodologias que podemos adotar para proporcionar um melhor ensino e aprendizagem aos alunos (FIORENTINI, 1995; LORENZATO, 2006).

Sendo assim, colocamo-nos as seguintes perguntas: o que podemos fazer, enquanto professores, para melhorar a situação da Educação no Estado do Tocantins? Como a Universidade pode contribuir para uma formação de professores qualificados/diferenciados que constituam variados conhecimentos teóricos, metodológicos e epistemológicos para utilizarem nas suas práticas docentes?

Simplificando estas indagações, restringimos à pergunta que norteará este trabalho, a saber, que perspectivas o PIBID proporcionou, especificamente, aos bolsistas de Matemática, com relação às práticas de ensino? Dando suporte a essa pergunta, seguem outras que tentaremos responder ao longo desse texto, a saber: o que podemos fazer, enquanto professores de matemática, para que haja melhorias no ensino e aprendizagem dessa ciência? Qual relação existe (e se existe) entre conteúdos específicos e o meio social em que os alunos estão inseridos? É possível proporcionar um ambiente de aprendizagem que envolva tanto os conteúdos específicos quando o meio social?

É com essas perguntas reflexivas que o Programa Institucional de Bolsa de Iniciação à Docência (PIBID) encarou as práticas e as discussões relacionadas ao ensino e aprendizagem da Matemática, em busca de alcançar um dos objetivos do Programa que é de "promover melhoria na qualidade da Educação Básica".

O que será apresentado neste trabalho são reflexões acerca das perguntas tecidas anteriormente, as quais surgiram como fruto de quase dois anos de participação no programa PIBID e de reflexões teóricas, baseadas principalmente nas idéias de Ubiratan D'Ambrosio e Ole Skovsmose. Em resumo, destina-se às contribuições do PIBID na formação de um professor diferenciado, que "pensa sobre" antes e após sua prática, consequência de várias discussões e reflexões com relação ao ensino da Matemática ${ }^{3}$. Mostramos também as influências que esse programa trouxe para os bolsistas da Matemática com relação às práticas

\footnotetext{
${ }^{3}$ Destacamos aqui as contribuições do grupo de pesquisa que atuamos intitulado "Ensino de Matemática", coordenado pelos professores José Ricardo e Souza Mafra e Fernando Guedes Cury, ambos da Universidade Federal do Tocantins - Campus de Araguaína.
} 
de ensino, de modo geral, à Educação Matemática. Tudo isso se direciona para o objetivo principal desse trabalho, que é de mostrar esse aspecto investigativo e reflexivo que os bolsistas do PIBID vivenciaram em sua formação inicial de professores de Matemática.

\section{O PIBID}

O Programa Institucional de Bolsa de Iniciação à Docência (PIBID) é um investimento do Governo Federal brasileiro por meio da Coordenação de Aperfeiçoamento de Pessoal do Ensino Superior (CAPES) nos cursos de licenciaturas em todo o Brasil, contemplando, em 2010, mais de 80 Instituições Federais com incentivos à docência ${ }^{4}$.

O PIBID tem como objetivos, segundo suas normativas:

I. Incentivar a formação de professores para a Educação Básica, especialmente para o Ensino Médio;

II. Valorizar o magistério, incentivando os estudantes que optam pela carreira docente;

III. Promover melhoria da qualidade da Educação Básica;

IV. Promover a articulação integrada da Educação Superior do sistema federal com a Educação Básica do sistema público, em proveito de uma sólida formação docente inicial;

V. Elevar a qualidade das ações voltadas à formação inicial de professores nos cursos de licenciaturas das Instituições Federais de Educação Superior;

VI. Estimular a integração da Educação Superior com a Educação Básica no Ensino Fundamental e Médio, de modo a estabelecer projetos de cooperação que elevem a qualidade do ensino nas escolas da rede pública;

VII. Fomentar experiências metodológicas e práticas docentes de caráter inovador, que utilizem recursos de tecnologia da informação e da comunicação, e que se orientem para a superação de problemas identificados no processo ensino-aprendizagem;

VIII. Valorização do espaço da escola pública como campo de experiências para a construção do conhecimento na formação de professores para a Educação Básica;

IX. Proporcionar aos futuros professores participação em ações, experiências metodológicas e práticas docentes inovadoras, articuladas com a realidade local das escolas.

Este programa foi dividido em vários projetos, cada Universidade, cada curso ou cada campus desenvolve um projeto em particular visando a alguns objetivos específicos. $\mathrm{Na}$ Universidade Federal do Tocantins, especificamente no Campus de Araguaína, existe um projeto que visa a um trabalho interdisciplinar. Nesse Campus, o objetivo específico do PIBID é tentar promover uma interdisciplinaridade, de acordo com os pressupostos de Fazenda (2002), entre as quatro áreas (cursos) envolvidas no projeto: Geografia, História, Letras e Matemática.

\footnotetext{
${ }^{4}$ Para melhores informações, conferir: <http://www.capes.gov.br/educacao-basica/capespibid > a Acesso em: 31 jul 2010.
} 
Com relação à interdisciplinaridade, sabemos que não é fácil de ser definida, entretanto, Japiassú (1976 apud RODRIGUES \& MARQUES, 2009) enfatiza que, para que ela aconteça, deve existir um grau de intensidade de trocas reais entre duas ou mais disciplinas no interior de um projeto. $\mathrm{O}$ ambiente educacional ou a metodologia adotada para promover a interdisciplinaridade foi o trabalho com projetos $^{5}$, de acordo com os pressupostos assumidos por Hernandez \& Ventura (1998).

Neste trabalho, não focalizaremos o próprio projeto em si, tampouco as práticas relacionadas à sala de aula, mas tentaremos ressaltar as influências que o PIBID proporcionou nos bolsistas da Matemática direcionadas à formação como Educadores Matemáticos. Nesse sentido, discutimos a ideia de tentar formar um cidadão que possa compreender o mundo criticamente, tanto social quanto culturalmente dando ênfase na conscientização. Isso consiste na essência do projeto ${ }^{6}$ (HERNANDÉZ; VENTURA, 1998).

Com isso, numa das atividades desenvolvidas, no ano de 2010, sobre a temática contemplada na metodologia de projetos, "Educação para o Consumo", percebemos que os encaminhamentos tomados por todo o grupo estavam tendendo à Educação Matemática ${ }^{7}$, aproximando-se da Modelagem Matemática ${ }^{8}$, isto é, havia uma preocupação contínua sobre como ensinar a matemática e que a mesma pudesse ser de acesso a todos, além de discutir qual Matemática necessitaria para trabalhar determinada problematização, tendo em vista a temática (LOPES, 2003; SKOVSMOSE, 1999, 2001, 2007).

\title{
Consumismo: processo de reflexão para a Educação Matemática
}

Para um melhor entendimento das reflexões aqui propostas, gostaríamos de enfatizar a principal ideia deste trabalho, trazendo algumas contribuições de Ubiratan D'Ambrósio (2005), com o qual nos identificamos bastante. Apesar da contextualização da passagem citada abaixo ser a respeito da História da Matemática, podemos, através de analogias com relação ao ensino e à aprendizagem da própria Matemática acadêmica, inseri-las em muitas situações. Nessa obra, D’Ambrosio (2005, p. 30) cita Dschuang Dsi e René Thom, que apontam:

\begin{abstract}
Havia um homem que aprendeu a matar dragões e deu tudo que possuía para se aperfeiçoar na arte. Depois de três anos, ele se achava perfeitamente preparado, mas, que frustração, não encontrou oportunidades de praticar sua habilidade.
\end{abstract}

(Dschuang Dsi)

Como resultado, ele resolveu ensinar como matar dragões.

(René Thom)

\footnotetext{
${ }^{5}$ Para que o leitor possa estar situado com relação às práticas (ou como aconteciam as atividades) desenvolvidas pelo PIBID, conferir: COSTA, et al. 2010.

${ }^{6}$ Destacamos essa ideia aqui, pois os objetivos do Programa não previam essa perspectiva, isso foi construído durante o desenvolvimento de pequenos projetos.

7 O PIBID era composto por 21 bolsistas (acadêmicos das áreas envolvidas), 4 professores da UFT (Coordenadores) e 4 professores do colégio onde desenvolvíamos as atividades (supervisores). Como estratégia, foram divididos os acadêmicos em 5 grupos, contendo um de cada curso. Cada grupo ficou responsável por uma turma de alunos e desenvolvia suas atividades no período vespertino.

${ }^{8}$ Para melhores informações conferir: BARBOSA; CALDEIRA; ARAÚJO, 2007.
} 
Com isso, percebemos semelhanças e analogias que podemos fazer com relação ao ensino acadêmico que recebemos, em especial, ao ensino e aprendizagem da própria Matemática. Historicamente, temos uma preponderância muito grande da Matemática Pura, em que se estuda uma Matemática mais abstrata e menos contextualizada, ou seja, o mais importante é relativo a provar teoremas e postulados, fazendo com que o ensino de Matemática seja para a Matemática e não um ensino voltado para as necessidades da sociedade, como algo que realmente tenha sentido para nossos alunos, promovendo uma educação pela matemática (FIORENTINI; LORENZATO, 2006).

Em consequência, da maneira com que a Matemática está sendo ensinada, surgem dificuldades em sua aprendizagem. A respeito disso, D'Ambrosio (2005, p. 31) destaca que:

\footnotetext{
É muito difícil motivar com fatos e situações do mundo atual uma ciência que foi criada e desenvolvida em outros tempos em virtude dos problemas de então, de uma realidade, de percepções, necessidades e urgências que nos são estranhas. Do ponto de vista de motivação contextualizada, a matemática que se ensina hoje nas escolas é morta. Poderia ser tratada como um fato histórico.
}

Tendo em vista estas felizes e bem colocadas palavras, a Matemática que aprendemos na Universidade não proporciona ao acadêmico - futuro professor - um momento de reflexão sobre o meio social que está inserido, onde os mesmos irão trabalhar com alunos e/ou pessoas que estão constantemente envolvidas com problemas sociais, econômicos e até mesmo culturais. "Isso não aprendemos na graduação!" (fala de um acadêmico do curso de Matemática inconformado com as metodologias de ensino e os conteúdos que são ensinados na Universidade). Costumamos dizer que "na Universidade, aprendemos no máximo a aprender a Matemática abstrata, porém, não nos é ensinado a ensinar a Matemática mostrando suas aplicações no dia a dia”. Não temos conhecimentos se outros autores já falaram isso, com essas palavras, para que pudéssemos referenciá-los, entretanto, essa frase gera inquietações e interesses sobre como estamos aprendendo e como nos é exigido ensinar esta ciência tão temida por muitos: a Matemática.

O que nos deixa mais inquietos é que antigamente a Matemática abstrata ou pura era vista no dia a dia, tinha sentindo para as pessoas, embora os seus praticantes ainda não soubessem que o que era praticado por eles era abstrato. Ou seja, os povos que viviam no Mediterrâneo e nas proximidades do Rio Nilo praticavam a Matemática que era útil para eles sobreviverem, para suprirem suas necessidades. E isso é muito interessante! Não se via essa dualidade, a contextualização, feita pela Educação Matemática e a Matemática Pura que nos confrontamos hoje em dia (D’AMBRÓSIO, 2005).

Do ponto de vista da Matemática e de estarmos diretamente ligados ao seu processo de ensino e aprendizagem, essas reflexões nos levaram a perceber que podemos pelo menos tentar proporcionar aos nossos alunos um ensino e uma aprendizagem da Matemática mais contextualizados no sentido de pensarmos, antes de tudo, em qual Matemática devemos ensinar-lhes em determinadas situações para resolver certos tipos de problemas ou para ser útil na sociedade.

Pensando nisso, nos momentos dos planejamentos do grupo, particularmente em que participavam um bolsista de Letras, História, Geografia e dois de Matemática, meio que implícito ou internamente, refletíamos sobre "como podemos contribuir para a aprendizagem desses alunos com nossos humildes conhecimentos matemáticos, tendo em vista que se trata de uma problematização a ser investigada?", ou melhor, "qual matemática esses alunos devem/necessitam saber para internalizarem certos conhecimentos sobre uma determinada 
situação-problema?". Perguntas como estas frequentemente eram feitas antes mesmo de desenvolvermos quaisquer atividades em sala de aula, uma vez que o nosso principal objetivo era proporcionar aos alunos uma metodologia de ensino diferente das aulas expositivas.

Como a temática era a Educação para o Consumo e como metodologia adotada no Programa seguia os pressupostos do trabalho com projetos, a problematização adotada pelos bolsistas, juntamente com os alunos, foi de tentar verificar ou investigar o valor da cesta básica que eles (ou suas famílias) consumiam durante um mês, e se a renda familiar de cada participante era suficiente para usufruir de uma cesta básica ideal ${ }^{9}$, que pudesse suprir as necessidades de uma família.

As atividades no colégio aconteciam nas terças e quintas-feiras no contraturno dos alunos (à tarde). Nas segundas e quartas-feiras, ocorriam as reuniões com todos os integrantes do programa (PIBID), onde eram feitos os planejamentos das aulas que seriam ministradas nos dias mencionados ${ }^{10}$. Aqui, destacamos um fator importantíssimo e primordial que direcionou as ideias da Educação Matemática, o "exercício de reflexão", relacionado com o papel da Matemática no desenvolvimento da investigação sobre a cesta básica. Consideramos esse momento como um fator essencial no processo de construção e implicação para um professor seguir os pressupostos da Educação Matemática.

Nesse momento, realizávamos um exercício que não foi proporcionado em nenhuma disciplina durante a graduação, consistindo em "refletir sobre a utilidade e envolvimento da Matemática com o meio social, político e cultural e seus possíveis impactos a partir da prática em sala de aula", ou seja, refletíamos sobre o papel da Matemática no cotidiano do aluno. Assim, sempre indagávamos, de que forma poderíamos inserir ou até mesmo como inserir alguns conteúdos matemáticos, de tal modo que contribuíssem para uma formação do cidadão crítico e consciente e que tenha significado explícito ou prático no seu processo de ensino e aprendizagem? Esse exercício, por sua vez, caracteriza-se como o exercício de reflexão a partir da prática (SHÖN, 1995, 2000). Isso instigou os bolsistas a praticarem um exercício contínuo de reflexão, por meio do qual a Matemática pode ser ensinada e aprendida num determinado momento do percurso das investigações sobre a problemática.

Distinguimos este aspecto reflexivo-investigativo como um fator diferençável no processo de iniciação à docência e, consequentemente, primordial para uma formação de futuros Educadores Matemáticos.

Por exemplo, após os alunos terem se deslocado até um supermercado local e pesquisado preços de vários produtos que poderiam compor uma cesta básica (um dos procedimentos tomados durante o desenvolvimento do projeto), e, após terem construídos tabelas num ambiente informatizado (laboratório de informática), com os respectivos valores desses produtos, pensamos e refletimos muito antes de propor qualquer pergunta que envolvesse a Matemática. Esses procedimentos ocorreram devido à metodologia de projetos adotada pelo programa (PIBID), proposta que, segundo Biotto Filho (2008, p. 19), “ não pode ser colocada em um molde único a ser seguido em todos os projetos, ou seja, podem surgir alguns questionamentos que devem ser resolvidos, mesmo não tendo sido planejado anteriormente".

Sendo assim, algumas perguntas que nortearam o projeto foram:

\footnotetext{
${ }^{9}$ Colocamos "ideal" devido ao desenvolvimento do projeto, pois uma das perguntas relacionadas à cesta básica era: "o que vocês desejariam que estivesse numa cesta básica?".

${ }^{10}$ Essas aulas eram ministradas para alunos do $6^{\circ}$ ao $9^{\circ}$ ano do Ensino Fundamental e para alunos do Ensino Médio Básico. No nosso caso, ministrávamos aulas para alunos do $1^{\circ}$ ano do Ensino Médio. Esta turma era composta por 15 alunos. Veja alguns registros no blog: http://pibiduftaraguaina.blogspot.com/.
} 
1) Dos produtos pesquisados, quais vocês consideram essenciais para estar presente numa cesta básica e que possam te sustentar com qualidade durante um mês?

2) Após responder a $1^{a}$ pergunta, monte uma tabela com os produtos que você indicou como necessários para que uma pessoa possa se alimentar bem e com qualidade no período de um mês.

3) E se a cesta básica fosse para manter sua família, como ficaria a lista e a tabela? (fazer uma tabela ilustrando).

4) Qual é o percentual dessa cesta básica - que vocês gostariam que fosse - e qual é o impacto mensal e anual com relação ao salário ou renda mensal de sua família? ${ }^{11}$ (esta pergunta será respondida após a realização da entrevista).

5) E se a cesta básica tivesse apenas esses alimentos citados abaixo, com suas respectivas quantidades, qual seria seu custo?

Tabela 1. Lista de alimentos com suas respectivas quantidades.

\begin{tabular}{lc|cc|cc}
\hline Alimentos & Quantidade & Alimentos & Quantidade & Alimentos & Quantidade \\
\hline Carne & $6 \mathrm{Kg}$ & Pão Francês & $6 \mathrm{Kg}$ & Batata & $6 \mathrm{Kg}$ \\
Leite & $15 \mathrm{litros}$ & Café em pó & 600 gramas & Tomate & $9 \mathrm{Kg}$ \\
Feijão & $4,5 \mathrm{Kg}$ & Óleo/banha & 1,5 litros & Açúcar & $3 \mathrm{Kg}$ \\
Arroz & $3 \mathrm{Kg}$ & Manteiga & 900 gramas & Farinha & $1,5 \mathrm{Kg}$ \\
\hline
\end{tabular}

Fonte: Alunos do Colégio Estadual Jardim Paulista e Bolsistas do PIBID.

6) Após tudo isso, como poderíamos representar graficamente essas tabelas? Tem como fazer isso? Se tiver como, o que precisamos saber/aprender de Matemática para fazermos esta representação? ${ }^{12}$

Essas perguntas nos levaram a refletir como inserir ou estudar alguns conteúdos matemáticos que pudessem auxiliar os alunos nas resoluções/investigações das perguntasproblemas que foram colocadas. Pensamos ainda em desenvolver ou direcionar a uma investigação, nos moldes da Modelagem Matemática, como foi colocado anteriormente ${ }^{13}$.

Tínhamos a intenção de inserir o conceito de função através destas investigações de tal forma que fosse construído e dado exemplos e contraexemplos de função, e, assim, explorar seus gráficos tanto na lousa quanto num ambiente informatizado ${ }^{14}$.

Não se trata de uma tarefa fácil. Tampouco conseguimos alcançar tudo que planejávamos. Pelo contrário, na maioria das vezes, não conseguíamos fazer esta relação e nem responder a essas perguntas reflexivas. Porém, o que pretendemos destacar com isso tudo é que esse cenário reflexivo muitas vezes, não nos é proporcionado e ensinado no decorrer da nossa formação inicial. E que, neste projeto, esse aspecto foi bastante visível e exercitado por muitos que ali estavam envolvidos.

Mesmo não alcançando nossos objetivos particulares com relação à aprendizagem dos conteúdos matemáticos, deixamos plantadas algumas sementes conscientizadoras com relação aos preços dos produtos que compõem uma cesta básica ou até mesmo as compras mensais das famílias e até que ponto pode ser economizado mensalmente nessa renda familiar, se for feito uma boa pesquisa em supermercados mais baratos.

\footnotetext{
${ }^{11}$ Sobre essa pergunta, elaboramos junto com os alunos uma entrevista para que fizessem com sua família na intenção de analisar a renda mensal com o valor da cesta básica que eles consomem. Não abordaremos essas entrevistas nesse trabalho para não perdermos nossos objetivos.

${ }^{12}$ Aqui nos referimos à matemática institucionalizada, ou seja, aos conteúdos escolares previstos no currículo.

${ }^{13}$ Isso não foi realizado devido a vários fatores, um deles foi que o objetivo do grupo era outro.

${ }^{14}$ Infelizmente, não alcançamos todos os nossos objetivos com relação à internalização dos conceitos específicos sobre função, tampouco diagnosticamos se os alunos tinham adquirido tais conhecimentos.
} 
A partir de todas as reflexões aqui apontadas, acreditamos possuir um peso contribuidor na formação do professor de Matemática, influenciando-o em suas futuras pesquisas e em sua postura como Educador Matemático.

\title{
EDUCADOR MATEMÁTICO
}

Os encaminhamentos desse trabalho nos trouxeram para a objetivação e reflexão sobre a questão da cidadania, apontando alguns caminhos para as concepções, tendências e abordagens da Educação Matemática. Desse modo, infinitas críticas são feitas à Matemática pela Matemática, inclusive para quem pensa numa Matemática para a cidadania - Matemacia (BIOTTO FILHO, 2008).

Com isso, acreditamos e seguimos os pressupostos da Educação Matemática, no sentido de que o educador matemático é aquele que concebe a Matemática como um meio, pois ele educa através da Matemática. Tem por objetivo a formação do cidadão e, devido a isso, questiona qual a Matemática e qual o ensino são adequados e relevantes para essa formação. Suas atividades se desenvolvem nas escolas de ensino fundamental e médio, nas Secretarias de Educação e nos centros de formação de professores. Sendo assim, o educador matemático é um profissional responsável pela formação educacional e social de crianças, jovens e adultos, dos professores de matemática (de nível fundamental e médio) e também pela formação dos formadores de professores. Suas pesquisas são realizadas, utilizando-se essencialmente fundamentação teórica e métodos das ciências sociais e humanas (LORENZATO \& FIORENTINI, 2006).

Nesse sentido, acreditamos que futuras melhorias com relação à qualidade da Educação, em particular, ao ensino da Matemática, serão alcançadas. Talvez aqui, com esses pensamentos, futuramente possamos obter nova visão sobre a própria Matemática no sentido de que,

\begin{abstract}
A educação Matemática, em especial, não se destina a formar matemáticos, mas sim pessoas que possuam uma cultura matemática que lhes permita aplicar a Matemática nas suas actividades e na sua vida diária [...] O professor deve saber propor a execução de projectos de trabalhos que utilizem conceitos matemáticos, ou saber 'agarrar' as ideias que os alunos proponham (MATOS \& SERRAZINA, 1996, p. 23).
\end{abstract}

Como intermédio disso, necessitamos de um professor investigativo e reflexivo. Esse profissional, assim entendemos, está constantemente sendo estruturado na formação inicial que o Programa PIBID proporciona.

Muitas críticas são feitas com relação ao ensino e à aprendizagem da Matemática, julgando esta área como impenetrável para muitos, e, ainda, afirma-se ser necessário a obtenção de um "Dom de Deus" para sua apreensão, isto é, predefine-se que poucas pessoas têm o privilégio de poder entender, manusear e ensinar matemática. Consequentemente, criase uma barreira entre a Matemática e o aprendiz Matemático - o aluno - quando, antes mesmo de tentar compreendê-la, o alunado se posiciona dessa maneira. Entretanto, apesar da Matemática possuir esse caráter, existem estudos e possibilidades de interferir nesse modo de pensar, entre eles, o movimento da Educação Matemática, movimento este que se preocupa 
com o impacto da Matemática no contexto social político e cultural, caracterizando-se como um meio de promover esta eventualidade.

Sendo assim, as contribuições que as concepções, tendências e abordagens da Educação Matemática defendem oferecem um suporte essencial para desenvolvermos tais atividades, já que as mesmas são constantemente exploradas através de leituras e discussões realizadas em eventuais encontros.

\title{
CONSIDERAÇÕES FINAIS
}

Tendenciosamente e evidentemente, percebemos que o fator reflexão esteve constantemente presente nas reuniões e discussões realizadas pelo grupo do PIBID, conforme abordamos ao longo desse trabalho.

Destacamos ainda que, no início das práticas vivenciadas em sala de aula pelos integrantes do PIBID, assim como até hoje ainda percebemos, o conceito de inovar ou diferenciar as práticas em sala de aula diz respeito simplesmente a não utilização da lousa ou ainda levar laptops e data shows para a sala de aula. Lembramo-nos de algumas contribuições e reflexões de D'Ambrosio (2005), quando ele traz um exemplo irônico sobre inovação dizendo o seguinte:

\begin{abstract}
É interessante tirar um pouco a impressão de que o professor inova simplesmente mudando o arranjo das carteiras na sala! Há pouco li num noticiário que haveria um grande progresso num sistema educacional: as autoridades arrumaram as carteiras de modo que não haverá mais aquele enfileiramento, agora será tudo em círculo! Mas no noticiário esqueceram de dizer se o professor continuaria quadrado ou não. É claro que com qualquer arranjo o professor pode se comportar da mesma maneira, pode continuar sendo autoritário, impositor, impostor - faz que sabe quando não sabe - e insensível aos alunos. O fundamental não é mudar o arranjo de móveis na sala, mas mudar a atitude do professor (p. 105-106).
\end{abstract}

É essa atitude, esse perfil, essa essência de ser professor que o PIBID proporciona para muitos que nele atuam, no sentido de olhar a prática como um momento único e influenciador nas concepções dos envolvidos no processo de ensino e aprendizagem. Esse aspecto também faz parte de um processo de construção de um professor reflexivo-investigativo na tentativa de sempre encontrar o novo ideal.

Para encontrar o novo em colaboração com os alunos uma das melhores estratégias é o método de projetos. Mas isso não exclui aulas expositivas, no estilo de conferência, que continuam tendo grande importância, em todos os níveis de escolaridade formal e não formal (D’AMBROSIO, 2005, p. 106).

Essas críticas também influenciaram nas reflexões sobre a própria prática docente. Em sua obra, o autor continua afirmando que "[...] aula expositiva não significa um professor falando e alunos ouvindo passivamente durante 50 minutos. Deve haver uma dinamização adequada." (D'AMBROSIO, 2005, p. 06). Tentávamos fazer isso constantemente nas atividades em sala de aula. Embora na maioria das vezes não utilizemos o quadro para poder estar ensinando aos alunos, uma vez que as aulas estiveram mais voltadas para a conscientização. 
Contudo, tudo isso que foi exposto ocorreu graças às ações que o PIBID proporcionou aos bolsistas envolvidos, em especial, aos da Matemática. Acreditamos que ações como estas fortificam a formação inicial do professor e que essas reflexões podem incentivar outros grupos de formação de professores ao repensarem novas práticas.

Desse modo, o PIBID oportunizou aos bolsistas uma reflexão diretamente ligada às práticas de ensino, em especial ao ensino da Matemática, principalmente com relação à importância e à necessidade de envolver os conteúdos específicos com a realidade do alunado, seu meio social, político e cultural. Só é possível proporcionar um ambiente de aprendizagem que envolva tanto os conteúdos específicos quanto o meio social se o professor tiver esse senso crítico e reflexivo sobre a importância de promover uma aprendizagem mais aberta ao mundo dos educandos e que supra com as necessidades da realidade de sua sala de aula.

\section{REFERÊNCIAS}

BARBOSA, J. C.; CALDEIRA, A. D.; ARAÚJO, J. L.(Orgs.). Modelagem matemática na educação matemática brasileira: pesquisas e práticas educacionais. Recife: SBEM, 2007. (Biblioteca do Educador Matemático, Coleção SBEM, v. 3).

BIOTTO FILHO, D. O Desenvolvimento da matemacia no trabalho com projetos. Dissertação (Mestrado em Educação Matemática) - Universidade Estadual Paulista Júlio de Mesquita Filhos, Rio Claro, SP, 2008.

COSTA, D. E. et al. O projeto PIBID e o desenvolvimento de ações relacionadas às práticas de ensino e a interdisciplinaridade na educação matemática. Anais do XV ENDIPE - Encontro Nacional de Didática e Prática de Ensino: convergências e tensões no campo da formação e do trabalho docente: políticas e práticas educacionais, Belo Horizonte, 2010. CD-ROM.

D'AMBROSIO, U. Educação matemática: da teoria à prática. 12. ed. Campinas: Papirus, 2005. (Coleção perspectivas em Educação matemática).

FAZENDA, I. C. A. Interdisciplinaridade: um projeto em parceria. 5. Ed. São Paulo: Edições Loyola, 2002.

FIORENTINI, D. Alguns modos de ver e conceber o ensino da matemática no Brasil. In: Zetetiké. Campinas, SP, Ano 3, n. 4, 1995.

FIORENTINI, D.; LORENZATO, S. Investigação em educação matemática: percursos teóricos e metodológicos. 3. ed. Campinas, SP: Editora Autores Associados, 2006.

HERNÁNDEZ F.; VENTURA M. A organização do currículo por projetos de trabalho. Porto Alegre: Artes Médicas, 1998. 
LOPES, C. A. E. (org.). Matemática em projetos: uma possibilidade! Campinas: Graf. FE/UNICAMP; CEMPEM, 2003.

LORENZATO, S. Para aprender matemática. Campinas, SP: Autores Associados, 2006. (Coleção Formação de Professores)

MATOS, J. M.; SERRAZINA, M. de L. Didática da matemática. Lisboa: Universidade Aberta, 1996.

RODRIGUES, G. M.; MARQUES, A. A. C. Movimentos da arquivística no processo de sua consolidação como disciplina: algumas considerações sobre interdisciplinaridade. Disponível em: < http://www.aargs.com.br/cna/anais/angelica_marques.pdf > Acesso em: 12 out de 2009.

SKOVSMOSE, O. Mathematical Agency and Social Theorising. Roskilde: Centre for Research in Learning Mathematics, Royal Danish School of Educational Studies, 1999.

. Educação matemática crítica: a questão da democracia. Campinas: Papirus, 2001.

Educação crítica: Incerteza, matemática, responsabilidade. Tradução de Maria Aparecida Viggiani Bicudo. São Paulo: Cortez, 2007.

SCHÖN, D. A. Educando o Profissional Reflexivo: um novo design para o ensino e a aprendizagem. Trad. Roberto Cataldo Costa. Porto Alegre: Artmed, 2000, 256p.

Formar professores como profissionais reflexivos. In: NÓVOA, A. Os professores e sua formação. 2. ed. Portugal (Lisboa): Publicações Dom Quixote, 1995. 